\title{
El SÍNDROME DE FUJIMORI
}

\section{FUJIMORI'S SYNDROME}

\author{
Martin Nizama V. ${ }^{1}$ \\ Universidad Nacional Mayor de San Marcos, Lima, Perú \\ (RECiBido el 02/02/2009, ACEPTADo El 24/06/2009)
}

\begin{abstract}
RESUMEN
Se describe los antecedentes históricos del proceso judicial al ex presidente Alberto Fujimori, tras haber sido extraditado de Chile, a donde llegó sorpresivamente, después de 7 años de su fuga al Japón, desde donde había renunciado por fax a la presidencia de la República. Se presenta la sinopsis del megajuicio, la teoría del autor mediato que sustentó tanto la extradición como la sentencia judicial de primera instancia, la cual determinó que el asesinato de las 25 personas fueron crímenes de Estado de lesa humanidad y que Fujimori tuvo dominio de un aparato organizado de poder para tal efecto. En la psicodinamia se establece la convergencia de la perversión narcisista y el desequilibrio paranoico en la comisión de los crímenes, así como la identificación de la víctima con el agresor: la víctima, el pueblo adicto a Fujimori, su verdugo; cuya hija Keiko es la candidata favorita a la presidencia de la República de ese electorado cautivo. Seguidamente, en el síndrome de Fujimori se sistematiza la fenomenología clínica observada en Fujimori, en su cúpula y en su entorno en el antes, durante y después del histórico megajuicio. Se concluye que el fenómeno Fujimori es un proceso mórbido que afecta la salud mental de los peruanos y se proponen alternativas preventivo promocionales para abordarlo.
\end{abstract}

Palabras clave: Salud mental y política, psiquiatría y política, violencia política, terrorismo

\begin{abstract}
The historical precedents of the prosecution of the ex president Alberto Fujimori it is described. He was extradited from Chile surprisingly, after 7 years of his fled in Japan, where he resigned by fax to the presidency of the Republic. The synopsis of the mega-judgment is shown, the theory of the mediator that stated both the extradition and the first sentence of the Magistrate's court (which established that the murder of the 25 people) were political crimes against humanity and that Fujimori was the master planner. In the psychodynamics the convergence of the narcissistic perversion and the paranoid imbalance is established, as well as the identification of the victim with the aggressor. The victim, the people addicted to Fujimori, their executioner which daughter Keiko is the favorite candidate to the presidency of this
\end{abstract}

1 Docente Principal de la Universidad Nacional Mayor de San Marcos,Lima-Perú.

E-mail: maniva@terra.com.pe 
eluded electorate. Therefore, in the Fujimori syndrome we can spot the clinic phenomenology observed in Fujimori and his inner circle before, during and after the historic mega-judgment. It is concluded that the Fujimori phenomenon is a morbid process that affects the mental health of the Peruvian people and preventive-emotional alternatives are suggested to deal with it.

Keywords: Mental health and politics, psychiatry and politics, politic violence, terrorism.

\section{INTRODUCCIÓN}

La histórica sentencia dictada en primera instancia por el tribunal San Martín el martes 7 de abril de 2009, desnudó por completo al súbdito japonés y ex presidente del Perú Alberto Fujimori Fujimori (AFF); al igual que a su cúpula, a sus fanáticos seguidores y a su estilo autocrático de hacer política. Todos ellos viven en su urna de mendacidad, cinismo, histrionismo y codicia de poder para beneficio propio. Cegados por la estulticia, rechazaron la ejemplar condena, producto impecable del megajuicio que se desarrolló en un escenario estrictamente jurídico, respetándose de manera escrupulosa, y a veces hasta en exceso, los derechos humanos del reo y el debido proceso. AFF fue condenado en el marco de un juicio legal, mas no en un juicio político; como tal, no es un atenuante el hecho supuesto que hubiese sido un buen gobernante en la lucha antisubversiva como presume él y sus prosélitos.

Tanto la Segunda Sala Penal de la Corte Suprema de Chile que concedió la extradición, como la Sala Penal Especial de la Corte Suprema del Perú que emitió la condena, sustentaron sus históricas decisiones en la teoría de la autoría mediata o teoría del dominio del hecho. El daño inferido a las víctimas, a la sensibilidad, dignidad y autoestima de los peruanos ha comenzado a ser reparado por la justicia, puesto que fueron crímenes de Estado. Y, para orgullo de la peruanidad es la primera vez que en la historia del país se juzga y condena a un ex dictador y a su cúpula delictuosa. AFF fue condenado como cabeza de un aparato de poder organizado que perpetró delitos en el marco de una estrategia de Estado.

Previamente, AFF había sido inhabilitado por 10 años para ejercer cargos públicos por incapacidad moral. Tras su increíble fuga (13-11-2000) al Japón y de haber renunciado a la presidencia de la República por fax desde Tokio (23-11-2000), ésta no fue aceptada por

el Congreso que lo sometió a juicio político por este motivo, inhabilitándolo. Siete años después de su fuga fue extraditado de Chile por la justicia peruana.

\section{Sinopsis del megajuicio}

1. Inicio: 10-12-2007. Fin: 07-04-2009.

2. Sentencia condenatoria adoptada por unanimidad: 25 años de cárcel.

3. Duración del proceso judicial: 16 meses.

4. Edad del condenado al dictarse sentencia: 70 años y 8 meses.

5. Transparencia: el juicio fue televisado íntegramente, hubo presencia de prensa extranjera y de observadores internacionales. 
6. Total de audiencias: 161 .

7. Número de folios de la sentencia: 711.

8. Número de pruebas: 500 .

9. Número de interrupciones por enfermedad del reo y de su abogado defensor: 6 .

10. Fundamentos que contiene la sentencia: 247.

11. Duración de la lectura de la sentencia: 3 horas.

12. Tiempo de impunidad hasta la emisión de sentencia: 17 años. .

13. Delitos sancionados: asesinato de 25 supuestos terroristas y secuestro de 2 personas.

14. Delitos tipificados en la sentencia: homicidio calificado, asesinato con alevosía, lesiones graves y secuestro agravado.

15. Criterio de conciencia de los jueces: certeza más allá de toda duda razonable

16. Reparación postrera: presunción de inocencia para los asesinados. La sentencia estableció que las víctimas no eran miembros de Sendero Luminoso (SL) ni terroristas.

17. Familiares emblemáticos: Raida Cóndor (madre) y Gisela Ortíz (hermana).

18. Presión política: asistencia regular al megajuicio de los 13 congresistas fujimoristas.

19. Sentencia vence el 10 de febrero de 2032 .

Así mismo, el Tribunal San Martín calificó como "próximos, precisos, graves y fundados" las pruebas indiciarias de que AFF supo de las órdenes impartidas por Hermoza Ríos y los crímenes de Colina comandados por el mayor EP (r) Santiago Martín Rivas, determinando que son crímenes de Estado de lesa humanidad. Ya, con anterioridad, la Comisión Interamericana de Derechos Humanos había establecido que estos crímenes no son sujetos de indulto ni amnistía.

Mas, AFF no fue sentenciado por su delito más grave, el autogolpe de Estado del 5 de abril de 1992, día en que con la fuerza bruta de los tanques destruyó el sistema democrático, felonía que ha quedado impune y que seguramente la historia juzgará.

De otro lado, la sentencia mereció el más amplio reconocimiento de la comunidad nacional e internacional y motivó que la sociedad peruana comience a recuperar la fe en la justicia. En este caso, el tribunal San Martín procedió con plena independencia y autonomía, lo cual ha contribuido a la elevación de la autoestima de los peruanos y a un incremento de la respetabilidad del Poder Judicial. También, la sentencia mereció el más amplio respaldo de diversas instituciones nacionales, entre ellas de la Facultad de Derecho y Ciencia Política de la Universidad Nacional Mayor de San Marcos y del Colegio de Abogados de Lima. 


\section{Teoría mediata}

Propuesta por el jurista alemán Claus Roxin (1963). Esta teoría fue aplicada por primera vez en 1963 para juzgar al criminal nazi Adolf Eichmann.

\section{Definición}

Autor mediato es quien hace ejecutar un crimen mediante otro sujeto cuya voluntad no es libre, y que se puede efectuar valiéndose de una estructura de poder organizada. El autor mediato dispone de una maquinaria para cometer multiplicidad de delitos con impunidad asegurada.

\section{Autor mediato}

AFF tuvo conocimiento y consintió la comisión de crímenes de lesa humanidad, ejecutados de manera selectiva por un aparato de poder organizado, el destacamento Colina, desde el Estado, en aplicación de una guerra sucia o guerra de baja intensidad, paralela a la guerra convencional contra el terrorismo desatado por Sendero Luminoso.

Así lo admitió en privado ante un grupo de congresistas el propio Montesinos (VMT): "Cuando se combatió el terrorismo habían cuatro ejes centrales: la primera era la decisión política. ¿A quién le correspondía eso? Al jefe de Estado, al Presidente. Si no había decisión política, nada funcionaba; o sea, si el estadista no definía el objetivo de erradicar la subversión, el aparato del Estado no andaba, y la violencia la tuvimos con el señor Belaúnde, con el señor Alan García, no hubo decisión política y al no haber decisión política nada se organizó" (1).

En el marco de esta estrategia, AFF avaló el simulacro de un proceso judicial a los integrantes del destacamento Colina en el fuero militar, el mismo que carecía de competencia para ello. Se les aplicó penas benignas, luego fueron amnistiados.

El tribunal San Martín estableció que AFF tuvo dominio de un aparato organizado de poder, que le permitió ejecutar una guerra de baja intensidad. Él estuvo detrás de la organización, ejecución y encubrimiento de los crímenes de Barrios Altos (domingo 3-11-1991) y La Cantuta (17-07-1992). Así lo apunta la sentencia en uno de sus fundamentos:

Fundamento 244: “¿Está probado que el acusado AFF estructuró y ejecutó una estrategia político-militar paralela a la que pregonaba públicamente, cuyo objetivo era la eliminación de terroristas, decisión que se articulaba por medio de su asesor Montesinos Torres y del aparato de poder organizado que formó?". "Sí lo está"

Él, en su condición de jefe supremo de las Fuerzas Armadas, tuvo mando y comando. En tal condición, a través de su asesor Vladimiro Montesinos Torres (VMT) y del jefe del Comando Conjunto de las Fuerzas Armadas, Nicolás De Bari Hermoza Ríos, ordenó, amparó y encubrió al escuadrón de la muerte. El encubrimiento fue político, judicial, mediático y sostenido. 
Así lo acredita el último acto de la cadena encubridora que instrumentó AFF, la Ley de Amnistía 26479. En la madrugada del día de la aprobación de dicha Ley, el congresista Henry Pease, impotente, ante la abrumadora mayoría fujimorista sólo atinó a vociferar en el pleno al presidente del Congreso, Ing. Jaime Yoshiyama: "Señor presidente, esta Ley es una infamia". Y, en aplicación a esta norma legal los ejecutores de los asesinatos quedaron libres. Ellos, habían sido sentenciados a penas leves no mayores de seis años por la justicia militar y las cumplían en cárceles doradas.

El mismo Henry Pease, ex presidente del Congreso, señala que "Los tres poderes del Estado y las FF. AA. actuaron en una misma dirección: encubrimiento total" y "si el jefe de ese Estado, con resortes legales e ilegales de poder, defendió paso a paso a los ejecutores del asesinato e hizo encubrir el crimen, paso a paso, es porque él mismo era parte del crimen". El mismo congresista Pease fue sindicado por Hermoza Ríos, cuando éste acudió al Congreso, de estar "coludido con el terrorismo". (El Comercio, 8 de abril, 2009)

\section{Argumento central de la sentencia}

AFF avaló, apoyó y autorizó el financiamiento estatal de una estructura organizada, el grupo Colina, por VMT y otros mandos, destinada a eliminar extrajudicialmente a supuestos subversivos de Sendero Luminoso y del Movimiento Revolucionario Túpac Amaru (MRTA). El tribunal San Martín determinó que:

1 Ninguna de las víctimas era terrorista.

2 Luego del asesinato, AFF felicitó a los integrantes del destacamento Colina y recomendó su ascenso por acciones distinguidas.

3 Hermoza Ríos sacó los tanques a las calles para intimidar a la oposición.

4 AFF obstaculizó la acción de la justicia mediante juicios simulados en el fuero militar, luego promulgó la Ley de la Amnistía.

5 Mayoría parlamentaria fujimorista encubrió la responsabilidad del gobierno y de los mandos militares.

6 La prensa independiente puso al descubierto la existencia del destacamento Colina.

\section{Psicodinamia}

Impulsado por su codicia irrefrenable de poder, AFF, con sutil astucia, supo entronizarse en el sentimiento popular; aquel pueblo víctima secular de la exclusión social, la baja autoestima, el pobre nivel cultural y las múltiples taras psicosociales de la gente. Y, con la máxima eficacia, explotó las necesidades más urgentes de los sectores sociales pobres y en pobreza extrema; así como el oportunismo de los empresarios anéticos, el neoliberalismo desembozado y la facilidad con la que se puede corromper a las cúpulas castrenses y a la alta burocracia estatal, para enquistarse en el poder, adulado y seducido por una cúpula de incondicionales. En ese contexto hubo una identificación de la autosubestimada víctima con su autoendiosado agresor. "Los perversos narcisistas suelen presentarse como moralizadores 
y suelen dar lecciones de rectitud a los demás; en tanto que "los paranoicos toman el poder por la fuerza, mientras que los perversos lo toman mediante la seducción". "La fase de violencia es en sí misma un proceso de desequilibrio paranoico: se debe destruir al otro porque es peligroso. Hay que atacar antes que ser atacado" (2).

Comúnmente, los peruanos viven acostumbrados a la desconfianza y a la corrupción generalizada, a los gobiernos autoritarios y a las ejecuciones extrajudiciales masivas, sin que la justicia sancione en rigor a los causantes de semejantes atrocidades. De modo que, por patético y paradójico que parezca, no los conmueve lo acontecido durante la década dantesca del fujimorato. Por el contrario, asumen con gratitud inquebrantable que el dictador fue "él único presidente" que hizo algo por ellos, admirándolo como un mesiánico que supo poner "mano dura" al desorden imperante. Por este motivo evaden, minimizan o escotomizan el lado negro del decenio de AFF. En este contexto, inconscientemente, hubo una identificación de la autosubestimada víctima con su autoendiosado agresor.

Hay en el pueblo peruano una frustración crónica causada por la ineptitud, la demagogia y aprovechamiento voraz de la clase política nacional. Inconscientemente, el pueblo necesita un salvador mesiánico, un padre tiránico que, de manera mágica o providencial, resuelva los graves problemas atávicos que arrastra el Perú por centurias. Por su inmadurez y miedo a la libertad, al pueblo le gusta obedecer y no está dispuesto a asumir responsabilidades cívicas ni políticas. Aprovechando este desajuste psicosocial, AFF demostró la facilidad con la que se puede corromper y avasallar a las FF. AA., a la burocracia estatal y a las instituciones; enquistarse en el poder, cometer feroces tropelías y luego ser aclamado por sus víctimas.

\section{RESULTADOS Y DISCUSIÓN}

\section{SÍNDROME}

A continuación se analizan los aspectos de la trama psicopatológica del antes, durante y después del megajuicio a AFF, cuyo decenio de gobierno dictatorial estuvo signado por un desembozado pragmatismo neoliberal, que condujo al Perú al desastre moral y a la depredación económica, por parte de una cúpula avara que pretendió enquistarse 20 años en el gobierno, con él en la cúspide del poder. A continuación, de manera secuencial se describe el síndrome de Fujimori $(3,4)$ :

\section{Antes}

\section{El origen del outsider Fujimori}

El antecedente más remoto del fenómeno Fujimori es el Plan Verde, elaborado por la cúpula militar a finales de la década del 80 , en los momentos en que parecía inminente que Sendero Luminoso tomara el poder del Estado por asalto, y el Perú era un infierno. Dicho plan castrense proponía la creación de un poder militar omnímodo en aras de una "causa superior", la derrota de Sendero Luminoso y el MRTA. Para ello, era necesario que el Estado domesticara a los peruanos convirtiéndolos en un colectivo social intimidado, sumiso y manipulable. Proponían una dictadura para operar de modo libérrimo y pacificar el país. 
Para lograr sus propósitos, la cúpula militar golpista necesitaba un outsider en la presidencia de la República para convertirlo en un instrumento manipulable al servicio de sus designios autoriarios. El entonces improvisado candidato presidencial AFF era el personaje ideal, por el arraigo popular que le acarreaba su imagen de honesto "chinito de la esquina", que subido sobre un modesto tractor de ingeniero agrónomo prometía "honradez, tecnología y trabajo”. Seguidamente, ocultos y siniestros poderes militares, empresariales y políticos tradicionales se coludieron para ayudarlo a acceder al poder de manera cuasi providencial, en la creencia de que lo iban a convertir en una figura decorativa.

Así, sin un plan de gobierno, sin partido político propio ni equipo de gestión gubernamental, aquel neófito presidente se encontró con un tsunami: terrorismo, narcotráfico, hiperinflación y una grave crisis social. No le quedó otra alternativa que recurrir a los militares que estaban prestos a acudir a su llamado y blindarlo contra la segura derrota ante el terrorismo, a cambio del cuartelazo camuflado que arrasó con la democracia. Este es el contexto completo en que se encontraba el Perú a principios de la oprobiosa década del 90: la anomia, el militarismo y el caudillismo de la mano. Este patrón aberrante ha sido una constante durante las 3/4 partes de los 188 años de vida republicana del Perú. Ello explica en parte por que los peruanos aplauden a las dictaduras por sus obras, sin importarles los latrocinios y crímenes que cometen. El autoritarismo es una peste endémica en el Perú. En este sentido es explicable, mas no justificable la comprobación de que al $40 \%$ de peruanos les da lo mismo vivir en democracia o en dictadura, lo cual revela carencia de valores cívicos en ellos.

El tipo de régimen político que condujo AFF fue el autoritarismo competitivo, que combina el mantenimiento formal de la legalidad democrática y una legitimación plebiscitaria que le permite ganar fácilmente los procesos electorales, con un funcionamiento autoritario por el cual el poder se concentra en la presidencia y que utiliza el respaldo popular con que cuenta para destruir la institucionalidad que lo controla, el equilibrio de poderes, los derechos de la oposición y de las minorías (Martín Tanaka. El fujimorismo como modelo. La República, 26-05-09), aplicando el principio maquiavélico, el fin justifica los medios.

Compartiendo la percepción de Sinesio López, el Perú se encuentra aún atrapado en el pantano fujimorista, cuyo signo es la carencia total del sentido ético de hacer política. AFF encarna el lado oscuro y sucio de la historia nacional, escenario en el cual campea la carencia de modales y la ausencia de la mediación de la institucionalidad en una década de crisis, terror, desconcierto y miedo. El ethos fujimorista es la política de la indecencia, del cinismo más abyecto, la viveza criolla, la pendejada, el hurto, las actitudes taimadas, la conducta solapa, el achoramiento y la lumpenización de su cúpula y operadores de su entorno. En el fujimorato se impuso el capitalismo salvaje por el cual se privilegió de manera desmedida la inversión y la acumulación de la riqueza, dejando de lado la distribución. Se impuso la autorregulación del mercado sin la autoprotección de la sociedad. AFF gobernó para los ricos con el apoyo de los pobres, que sólo recibieron migajas. Su modus operandi fue la captura y la desnaturalización de las instituciones de control estatal, social y ciudadano, mediante el sofisticado arte de robar y encubrir (Ética y Política, $L a$ República, 17 de abril 2009). 
En la actualidad, el Perú viene saliendo lentamente de un prolongado período de más de 20 años de graves conflictos de guerra interna y de la década dantesca del fujimorato, período en el cual los movimientos populares fueron impelidos a situaciones desesperadas por los grupos fundamentalistas, los nacionalismos radicales y el pragmatismo neoliberal fujimorista.

\section{Codicia de poder}

Cabe preguntarse ¿por qué regresó AFF al Perú?, abandonando su confortable y seguro refugio en Japón donde disfrutaba de su riqueza malhabida. Seguramente su hambre irrefrenable de poder lo hizo creer que sería recibido en olor a multitud; que el pueblo impediría que lo juzguen, y que estaba predestinado para ocupar nuevamente el sillón presidencial para un tercer período de gobierno. Es probable que así lo haya persuadido su cúpula de aduladores, que también sueña con recuperar los cargos públicos para usufructuarlos y enriquecerse fácilmente. Pero todo terminó en un estrepitoso fiasco y el autopublicitado "estratega genial" que todo lo calculaba, acabó en la prisión con una severa condena de 25 años. Una vez más queda establecido que la codicia de poder envilece y hasta hace perder la conciencia y el juicio de realidad a los adictos a este mágico embleso.

\section{Cúpula de poder}

La cúpula de poder fue un triunvirato anético que encabezaba AFF en una relación simbiótica con su clon VMT, quien en su condición de omnímodo asesor era el nexo con las FF. AA. comandadas por Nicolás De Bari Hermoza Ríos. Durante ocho años este triunvirato y sus cómplices saquearon el tesoro público, entre abril de 1992 y noviembre del 2000. Sus actividades vedadas fueron el enriquecimiento ilícito, la eliminación de adversarios políticos, el transfuguismo, la compra y amedrentamiento de jueces y la compra de cargos públicos, entre otras. También, mediante el soborno y el chantaje controlaban los medios para manipular a la opinión pública, distrayéndola de manera abyecta con viles operativos psicosociales. Desacreditaban a los opositores políticos mediante la prensa amarilla y campañas mediáticas montadas de manera selectiva. Ejercieron con maestría el canibalismo mediático para demoler a los opositores.

\section{Cobardía}

AFF fugó al Japón, su país de origen, porque según él "temía por mi vida". Abandonó a su hija Keiko Sofía Fujimori Higuchi en el Palacio de Gobierno, quien era la primera dama de la nación, y dejó en la más desnuda orfandad a sus cómplices políticos. Aquí es acertado el pensamiento de Michael de Montaigne: "la cobardía es madre de la crueldad".

\section{Impunidad}

El autócrata sólo cree en la impunidad para él y sus secuaces. Una vez producidos los crueles asesinatos, AFF felicitó a los integrantes del escuadrón de la muerte Colina, recomendó su ascenso por acciones distinguidas y los favoreció con la amnistía y la prescripción, limpiándolos. 


\section{Saqueo del tesoro público}

La Procuraduría Anticorrupción estableció que durante la década 1990-2000 el saqueo del Tesoro del Estado fue de 2,000 millones de soles y solamente han sido recuperados apenas 130 millones de soles. Esta depredación pérfida incrementó drásticamente el índice de pobreza de los excluidos, quienes paradójicamente se identifican con el autócrata, debido a que supo seducirlos con obras públicas financiadas con los sobrantes de la exacción del erario nacional. Es la cara oscura del "fujimorismo económico". La mejor manera de robar de los corruptos es haciendo obra; puesto que así se benefician de la sobrevaloración de las mismas, y construyen en el imaginario social la espuria imagen de benefactores del pueblo. Al respecto, la expresión popular que reza: "habrá robado pero ha hecho obra", es una justificación amoral del colectivo social.

\section{Prepotencia}

Cuando los fujimoristas fueron mayoría política en el Perú y la sociedad civil se encontraba embelesada por el autoritarismo del caudillo Fujimori, entonces la oposición era una minoría duramente atacada por la prensa comprada por el régimen. Toda la gestión gubernamental se manejaba con un verticalismo implacable blindado por el secretismo.

\section{Fujimorización}

La frágil democracia peruana fue secuestrada por la tarántula fujimorista, lo cual implicaba una relación directa entre los grandes poderes económicos y las cúpulas políticas. Así, la toma de decisiones se daba al margen de la institucionalidad, las normas, las leyes y de la voluntad ciudadana. Esta relación se estableció vía lobbies y mediante otros canales vedados e informales.

\section{Guerra de baja intensidad}

AFF tuvo dominio de un aparato de poder organizado que planificó, organizó, ejecutó y encubrió a los operadores de la guerra sucia. Clandestinamente, y en forma paralela, él ordenó la implementación de una guerra de baja intensidad o terrorismo de Estado: torturas, desapariciones forzadas, ejecuciones extrajudiciales y encarcelamiento de inocentes con sentencias desproporcionadas. Lideró la "nueva estrategia" contrasubversiva y en ese rol impulsó personalmente el inicio de su implementación con su presencia en las universidades La Cantuta, San Marcos y del Centro, con su participación en la entrega de armas a las rondas campesinas, y con su presencia en las acciones cívicas en las zonas de emergencia. Igualmente, por su paseo macabro sobre los cadáveres de terroristas rendidos y cruelmente rematados, hechos que lo sindican como autor mediato de semejantes atrocidades.

\section{Adherencia de la población}

La autocracia fujimorista, para contrarrestar la estrategia senderista de conquistarse a la población, comenzó a realizar obras de infraestructura en las poblaciones rurales más 
alejadas, suministrarles alimentos gratuitamente y obsequiarles ropa. Así se ganó la confianza y el apoyo de ellos, que comenzaron a volverse contra las huestes senderistas, a la par que implementaba la guerra sucia para la eliminación selectiva de supuestos subversivos. Entonces se dio el síndrome de Pinochet: tolerancia social con la violación de los derechos humanos en aras del orden y seguridad, y reprobación de la corrupción por parte de la población.

\section{Autoritarismo mesiánico}

Ancestralmente, grandes sectores de la sociedad peruana, principalmente, los excluidos han creído ciegamente en el gobierno de "mano dura". Prefieren un dictador porque piensan que éste "tiene los pantalones bien puestos", sabe poner orden y es el único capaz de salvar al país de la anomia (caos). De manera astuta AFF desacreditó la democracia, la "partidocracia" y a los "políticos tradicionales". Hizo creer a la población que la única manera de derrotar a Sendero Luminoso era aplicando mano dura y que sólo él podía lograrlo. Los fujimoristas activamente publicitan a AFF como el salvador del Perú de las "garras del terrorismo" y de la grave crisis económica en que lo encontró. Para el efecto, su asesor VMT le organizó un eficaz servicio de inteligencia que le permitió estar siempre un paso más adelante de todos y anticiparse, afirmando de este modo la tradicional cultura autoritaria vigente en el país.

\section{Escuadrón de la muerte}

El plan Cipango de las FF. AA. fue la partida de nacimiento del escuadrón Colina, comandado por el operador Santiago Martín Rivas, el cual en el lapso de 15 meses (noviembre 19991- octubre 1992), mediante nueve operativos planificados y ejecutados con vesania, asesinó extrajudicialmente a 50 personas indefensas. Una de estas masacres fue el vil asesinato de 5 miembros de la familia Rodríguez Páucar, acusados de ser presuntos miembros de Sendero Luminoso. El crímen fue perpetrado en la madrugada del 23 de enero de 1992 en la vivienda de dicha familia, ubicada en el Asentamiento Humano Señor de los Milagros de la campiña de Huaura. Las víctimas fueron masacradas mientras dormían. Otros crímenes emblemáticos de Colina fueron el asesinato de los hermanos Ventocilla Castillo, del periodista Pedro Yauri, el descuartizamiento de Mariella Barreto Riofano, la tortura de Leonor La Rosa, el asesinato de Saúl Cantoral y de Pedro Huilca Tecse. También, la eliminación física de 7 campesinos de Humaya y Chambara, y del alcalde de Huaura, Jesús Morales Bermúdez (Caretas, 14 de mayo de 2009). Mostrando su interés por este escuadrón de la muerte AFF preguntaba a menudo: "Cómo está el grupito?"

\section{El silencio del miedo}

Con el propósito de mantener el miedo en la población, tras el golpe de Estado del 5 de abril de 1992, la dictadura de AFF recordaba la existencia de los remanentes senderistas. Sabido es que una sociedad sometida al imperio del miedo es fácilmente manipulable. Igualmente, el fujimorato internalizó en el imaginario social la idea de que la oposición es sinónimo de terrorismo, de modo que quien hablaba contra el gobierno era terrorista; y el terrorista es un enemigo al que se le arresta, condena o asesina sin ley. De modo maquavélico, AFF 
justificaba esta situación, así: "Lo que el Perú necesitaba era orden, disciplina, principio de autoridad, buen manejo y un puño de hierro contra el terrorismo" (5).

Luego de la denuncia de la matanza de La Cantuta en el Congreso, el general Hermoza Ríos sacó los tanques desde Chorrillos hasta el Rímac, para intimidar a la oposición, lo cual provocó una enérgica reacción internacional de rechazo. Una sociedad sometida por el imperio del miedo es fácilmente manipulable y el ciudadano opta por el silencio, aún cuando esté en desacuerdo con las fechorías del tirano de turno.

\section{Conveniencia de la violencia terrorista}

La violencia fue utilizada por AFF para enquistarse en el poder; sea sobredimensionando hechos subversivos, inventándolos o difiriendo de manera calculada la captura de Abimael Guzmán y de su cúpula. De esta manera mantuvo a la población en estado de miedo y sumisión, y esta no tuvo otra alternativa que apoyarlo. Así, dictadura y subversión se necesitaban mutuamente para subsistir. Al gobierno le convenía para evitar la reformas profundas del Estado y medrar con la lucha contra la subversión.

\section{Cinismo e inhumanidad}

El acmé del cinismo e insensibilidad del fujimorato ocurrió en el Congreso de la República, cuando la mayoría gobiernista aprobó el informe de los fujimoristas Freundt y Siura, en el cual llegaban a sostener que los estudiantes de La Cantuta se habían jautosecuestrado!”. Ello fue repetido por la congresista Martha Chávez. También, ha quedado grabada en la retina de los peruanos la imagen de la guiñada cómplice entre AFF y VMT, durante el affaire de su careo en el megajuicio. AFF había sostenido durante el juicio que sólo lo unía a Montesinos relaciones de trabajo.

El psicoanalista Alberto Péndola, al analizar la guiñada de ojos entre ambos "siameses" durante su confrontación en el megajuicio, señaló lo siguiente: "Fujimori se delató en esa audiencia. Nos hizo un gran favor al mostrarnos, mediante sus gestos, la relación de cercanía que tenía con Montesinos. No obstante, los fujimoristas siguen insistiendo en que dicha relación jamás existió. Ellos están renegando la percepción de algo evidente".

\section{Sufrimiento masivo}

Miedo, inseguridad ciudadana, delincuencia, distorsión de valores, mentiras, desprecio al ciudadano, corrupción y degradación de las instituciones, fue lo que prevaleció en el escenario social, luego del autogolpe de Estado perpetrado por AFF y la cúpula militar.

\section{Doble juego de los Estados Unidos}

El gobierno norteamericano fue desleal a la democracia que predica para el Tercer Mundo. Por un lado el Departamento de Estado condenaba la política de la violación sistemática de los derechos humanos implementada por la dictadura; mientras que por el otro lado, la 
DEA suministraba cuantiosa ayuda económica al gobierno en la guerra contra las drogas y la CIA apoyaba incondicionalmente a VMT, jefe de facto de los servicios de inteligencia gubernamentales.

\section{Durante}

\section{Inicio del megaproceso}

El inicio del megajuicio la marcó la teatralidad de AFF. Con gran aspaviento consagró el tiempo de su primera intervención a hacer una impertinente apología a su gobierno. El juez supremo César San Martín tuvo que conminarlo al orden manifestándole con firmeza: "Aquí mando yo", merced a lo cual recién AFF culminó su estridente alocución, vociferando: "Rechazo los cargos. ¡Soy inocente!”.

\section{Carencia de autocrítica}

Durante el prolongado y tedioso proceso judicial, AFF fue incapaz de mostrar algún grado de autocrítica. En todo momento su actitud fue "cero autocrítica". En su alegato final reiteró: "Mi estrategia de pacificación fue la correcta y ¡no me arrepiento!". Sin capacidad de autocrítica ni de sentir culpa, ¿puede gobernarse una nación y pretender volver a hacerlo?

\section{Negación}

En el proceso judicial AFF se limitó a pretender engañar al tribunal con respuestas evasivas y lacónicas como "No sé", "No me acuerdo", "Me acojo al derecho de silencio". También sostuvo con teatralidad: "¡Soy inocente!”, “¡Yo no sabía nada!”.

Por su parte, el congresista fujimorista Rolando Souza, ante la pregunta periodística, "Le parece creíble la versión de que Fujimori no sabía lo que hacía Montesinos, que era su brazo derecho?", sorprendió con esta respuesta: "Yo no sé qué es lo que está haciendo mi esposa en este momento. Nadie sabe lo que hacen su esposa e hijos. Con mayor razón, no es imposible que Fujimori no supiera lo que hacía Montesinos" (La Primera, 18-05-2009)

\section{Narcisismo}

El espejismo de sí mismo acerca de su hipertrofiada autoestima personal, lo revela su arrogancia verbal de sumo hacedor: "Yo me involucré directa y personalmente", "Me precio de ser un hombre de retos y decisiones", "Mi escenario de trabajo es resolver los problemas imposibles", "Mi línea era el pragmatismo".

\section{Mendacidad}

Siguiendo la máxima atribuida al jerarca nazi Joseph Gobbels: miente, miente, que algo queda, AFF en su alegato final dijo: "Fue un grupo de militares el que boicoteó mi estrategia de pacificación", en alusión al destacamento Colina, contradiciendo su afirmación de que 
en política "No hay caídos del palto", cuando ejercía el poder.

\section{Incapacidad de sentir culpa}

En su alegato final, demostrando una pseudo culpa, AFF expresó: "Me duele en el alma las muertes y excesos aislados que le dieron en sentido contrario de la directiva de pacificación”.

\section{Maquiavelismo}

El leitmotiv no verbalizado de AFF, como autor mediato de los crímenes que ordenó, era la razón de Estado, lo cual fue corroborado por VMT en el tribunal cuando el fiscal le preguntó si en nombre de la razón de Estado se pueden cometer delitos, él secamente respondió: "Sí". De modo que, en virtud de la lógica de que el fin justifica los medios, AFF asumió una lucha sin cuartel contra la subversión, optando por la "Ley del todo vale". En su alegato final AFF no hizo el deslinde con VMT ni con Hermoza Ríos y cargó con el pasivo de ambos personajes siniestros.

\section{Mesianismo}

AFF asumió de por sí y ante sí mismo el rol de líder predestinado e iluminado; el que de manera providencial salvó al Perú de la hiperinflación, lo pacificó e impuso el orden mediante el uso implacable del poder. Por ello, exige que los peruanos le guarden eterna gratitud; a él y a su dinastía plasmada en sus hijos Keiko y Kenyi, etc.

\section{Después}

\section{Furia}

Keiko y Kenyi, sus hijos, el mismo día de la sentencia llamaron a un alzamiento popular. Desde Tokio, Satomi Kataoka, su actual esposa clamó que AFF "es un samurai con ADN japonés". Perdiendo la sensatez, manifestaron que la condena a su mentor es un triunfo del terrorismo o simplemente "una cojudez". Todo ello, teniendo como marco alegórico las histriónicas estridencias de la portátil naranja, los denominados carapintada" o "guardianes del chino", comandados por un coronel retirado del ejército.

\section{Impacto de la sentencia}

"Está probado que...?”. "Sí, lo está”. Estas frases leídas con voz firme por la letrada Yanet Carazas Garay, relatora del tribunal, durante la histórica lectura de la sentencia, sonarán por largo tiempo en los oídos de los peruanos, no acostumbrados a presenciar este tipo de actos de justicia acometidos de manera impecable por jueces probos. El Perú fue sacudido por esta experiencia sorprendente y grata. Igualmente, el mundo fue impactado por este acontecimiento y medios de la mayor jerarquía como The New York Times, Financial Times y Wall Street Journal destacaron el justiciero desenlace del proceso judicial peruano. 


\section{Percepción democrática}

Para el ex Ministro de Educación, Nicolás Lynch, el Perú político y democrático opinó acerca de la sentencia desde tres tipos de percepciones:

- La primera, de rechazo a la condena por parte de los fujimoristas y de una parte de la derecha peruana, quienes propugnan una "democracia de baja intensidad", limitada a elegir gobiernos que ellos puedan controlar, subordinando a su voluntad a los poderes legislativo y judicial. Así, la democracia es una manera de administrar sus intereses y privilegios. Es el gobierno de los ricos con el apoyo de los pobres. Para ellos, es inaceptable la muestra de independencia del Poder judicial en la condena a Fujimori. Es una "desviación" que se debe revertir de inmediato para retornar a la situación de los jueces domesticados al servicio del poder de turno. Al respecto, el periodista Jaime de Althaus escribió: "es injusto....el solo hecho de que a Fujimori se le haya procesado por derechos humanos...pero en el tema de los derechos humanos, Fujimori humanizó la lucha contra el terrorismo" (El Comercio, 10 de abril, 2009).

- La segunda, de aceptación de la condena por parte de gente del centro y de la derecha para quienes la sentencia revela una saludable independencia del Poder Judicial. Así mismo, piensan que la democracia no es solamente gobiernos elegidos, sino también Estado de derecho: imperio de la Ley e independencia de poderes.

- Y, la tercera, de sectores de izquierda, la condena no sólo es una muestra de independencia del Poder judicial; también, es la condena a la dictadura lo cual conlleva a la necesidad de que los gobiernos elegidos deben asumir los derechos sociales en favor del bienestar de la población (La República, 23 de abril, 2009).

\section{Manipulación}

Una encuesta de CP, I publicada al día siguiente de pronunciada la sentencia, mostró que el $69 \%$ de los encuestados aprobaba que AFF haya sido sentenciado y el 26,2\% consideraba que se le debió absolver por ser inocente. Del $69 \%$ que aprobaba la sentencia, 36,2\% estuvo de acuerdo con los 25 años que le dieron; el 28,5\% respaldó la sentencia, pero que le daría menos años y un 4,3\% opinó que debieron darle más de 25 años. Sin embargo, en los medios de comunicación fujimoristas, de manera tramposa y por arte de birlibirloque se hizo una lectura amañada de las cifras, con el evidente propósito de manipular a la opinión pública, pretendiendo engañarla en el sentido que el $59.4 \%$ de los encuestados estaba en desacuerdo con la sentencia. Socarronamente, el periodista César Hildebrandt, refiriéndose a estos sondeos de opinión, las denominó "putiencuestas" (La Primera, 10 de abril, 2009).

Otra forma de manipulación burda del colectivo social lo constituye la presencia sistemática en el megajuicio de una supuesta vidente, la anciana Salomé Ibarguen de 87 años, publicitada como especialista en tarot y ciencias ocultas. Predijo que el "Chino" "saldrá libre de polvo y paja”. Los fujimoristas son avezados en el mañoso arte de los operativos psicosociales. 


\section{Reconciliación del Poder Judicial con la ciudadanía}

Según una encuesta seria, el $70 \%$ de la opinión ciudadana estuvo de acuerdo con la culpabilidad de AFF por los crímenes de Barrios Altos y La Cantuta, y de los secuestros en los sótanos del Servicio de Inteligencia del Ejército; mientras que el 50\% aprobó el desempeño del juez Dr. César San Martín Castro y, por ende, del Tribunal que lo juzgó; el 53\% consideró que ello contribuiría a mejorar la imagen del Poder Judicial que, en dicho sondeo de opinión, obtuvo un inusitado $27 \%$ de aprobación. Por su lado, el Fiscal Avelino Guillén obtuvo el $46 \%$ de aprobación y el Fiscal José Peláez Bardales logró el $43 \%$ de aceptación; y un $27 \%$ de los encuestados cree que AFF es inocente, principalmente en los segmentos socioeconómicos D y E (Ipsos Apoyo, El Comercio, domingo 19 de abril de 2009).

El Poder Judicial y el Ministerio Público estuvieron dignamente representados en el mega juicio, de la siguiente manera: Tribunal: César San Martín Castro, presidente; Víctor Prado Saldarriaga y Hugo Príncipe Trujillo. Fiscales del proceso: titular, José Antonio Pelaez Bardales. Adjunto, Avelino Gullén Jáuregui.

Históricamente, el Poder Judicial y el Ministerio Público necesitaban deslindar con el denigrante sometimiento de sus fueros al fujimontesinismo de la década del 90.

\section{Descalificación de los jueces}

Apenas leída la sentencia, el iracundo entorno fujimorista lanzó toda clase de improperios contra el Poder Judicial, particularmente contra los jueces que juzgaron a su líder, a los cuales amenazaron. Así, Keiko Fujimori manifestó: "La condena impuesta a mi padre está llena de odio y venganza". "No hay nada que esperar de este poder judicial que no sirve para nada"; todo "es una farsa", acotando que la condena a su padre es un triunfo del terrorismo; para Santiago Fujimori "la condena es un triunfo para Sendero Luminoso". Un líder de ellos había manifestado que no aceptarían un fallo prevaricador que condenara a Fujimori; otro más radical opinó que "el fallo es putrefacto". Un representante militar manifestó: "nos han convertido en una banda de asesinos". Y, extrañamente el abogado Nakasaki lanzó la peregrina idea de que los jueces que juzgan a AFF, en su mayoría son de la Universidad Nacional Mayor de San Marcos y, por tanto, son izquierdistas. Un prejuicio estigmatizante.

Por su lado, en base a prejuicios ideológicos, el Dr. César Nakasaki, abogado de AFF, cuestionó anticipadamente al presidente de la Primera Sala Penal Transitoria de la Corte Suprema, Dr. Duberly Rodríguez, la misma que resolverá el pedido de nulidad de la sentencia dictada contra AFF en primera instancia. Nakazaki acusó a Rodríguez de carencia de imparcialidad, por haber acompañado al presidente del Poder Judicial, Dr. Javier Villa Stein, en una conferencia de prensa en la cual éste expresó su rechazo al proyecto de Ley de la Carrera Judicial. Villa Stein aclaró que la presencia de César San Martín y Duberlí Rodríguez en dicha conferencia de prensa fue para mostrar el apoyo de la presidencia del Poder Judicial a los jueces, mas no a la condena porque según él la sentencia se explica por sí misma. Por este aparente motivo, Nakasaki amenazó con recusar al juez supremo Rodríguez. 
Luego de haberse dictado la sentencia en primera instancia, los voceros políticos y mediáticos fujimoristas comenzaron una campaña para desacreditar al presidente de la Sala que verá la apelación en última instancia. El primer paso de su estrategia fue pretender estigmatizar al juez Rodríguez por su pasado como militante de izquierda radical, sin percatarse que como tal fue elegido democráticamente diputado nacional por Izquierda Unida (1985-1990). Su propósito es descarado: tachar a Rodríguez y retirarlo de la Sala de apelación u obligarlo a que se inhiba, para que sea reemplazado por un magistrado filofujimorista que posibilite la anulación de la sentencia o reducirla drásticamente.

Los miembros de la Primera Sala Penal Transitoria que resolverá el pedido de nulidad de AFF, la preside Duberlí Rodríguez Tineo y la integran los vocales Julio Biaggi Gómez, Elvia Barrios Alvarado, Roberto Barandiarán Dempwolf y José Neyra Flores.

\section{Represalias contra el Poder Judicial}

A las 3 p.m. del 7 de abril de 2009, día en que se dictó la severa sentencia contra AFF, la Comisión de Justicia del Congreso de la República aprobó el dictamen de la Ley de la Carrera Judicial, por el cual se recortaban las atribuciones del juez y se incrementaban las causales de destitución; propuesta que fue rechazada por la Sala Plena de la Corte Suprema, y provocó la enérgica protesta del Presidente de la Corte Suprema de Justicia, Dr. Javier Villa Stein, quien por este motivo se presentó ante la prensa acompañado del juez Dr. César San Martín y del presidente de la Primera Sala Penal Transitoria de la Corte Suprema, Dr. Duberlí Rodríguez Tineo, que resolverá la apelación de la sentencia a AFF.

El dictamen comprende la evaluación de los jueces cada tres años y medio, y considera sanciones administrativas a los jueces que declaran a los medios sobre procesos en trámite. Esta situación amenazó con una confrontación entre ambos poderes del Estado. Otro hecho de tensión es el bloqueo o retardo del levantamiento de la inmunidad parlamentaria a algunos legisladores con problemas judiciales, como el caso del congresista Carlos Raffo por el caso de receptación de dinero a VMT para la campaña electoral. Entre tanto, miembros de la cúpula fujimorista afirmaron ante los medios de comunicación social que la Sala que verá la apelación en segunda instancia estaba parcializada, puesto que según ellos estaba integrada por jueces que defendieron terroristas o que estarían resentidos al haber sido destituidos tras la intervención del Poder Judicial el 5 de abril de 1992. El objetivo encubierto es desactivar la actual Sala de segunda instancia para reemplazarla por jueces digitados, complacientes y sumisos.

\section{Recusación al Tribunal}

Sin ambajes, AFF recusó al tribunal San Martín que lo juzgará en el juicio por indemnización mediante la Compensación por Tiempo de Servicio (CTS) a favor de VMT. Acusa a estos jueces dignos y probos de estar contaminados por haberle dado la sentencia de 25 años. El propósito encubierto de esta estrategia abogadil, es dilatar el proceso judicial hasta el 2010, año electoral y de cambio de la mesa directiva del Congreso nacional. En esa coyuntura política buscarían cambiar la composición de la Sala que juzgaría al autócrata, en busca de jueces venales o complacientes. 
Sin embargo, el 22 de mayo del 2009, la Sala Penal Especial de la Corte Suprema rechazó la recusación de los vocales César San Martín y Víctor Prado y sólo aceptó la recusación del vocal Hugo Príncipe como juez del proceso por el tema de la CTS, por la cual AFF pagó irregularmente 15 millones de dólares a VMT, para que abandonara el cargo de asesor presidencial. Hugo Príncipe será reemplazado por otro vocal.

\section{Resistencia y desobediencia a la autoridad}

El publicista y congresista fujimorista Carlos Raffo, amparándose en la inmunidad parlamentaria, muestra una abierta rebeldía para asistir a las citaciones que le ha formulado la 4ta Sala Penal Anticorrupción, en el juicio que se le sigue por recibir 150 mil dólares de VMT para realizar su campaña electoral. Respecto a la negativa de Raffo, el presidente de la Corte Suprema, Dr. Villa Stein, manifestó: "Espero que el Congreso haga respetar el orden jurídico, porque esas son manifestaciones golpistas que rechazo" en contra del Poder Judicial. Con ello quedó evidente el autoritarismo antidemocrático de este político. El presunto delito lo habría cometido antes de que Raffo fuera congresista.

\section{Derrota de la subversión}

La guerra de baja intensidad no fue la que derrotó al terrorismo. Este fue vencido merced a la captura de Abimael Guzmán Reynoso y del Comité Central de Sendero Luminoso (Domingo 12-09-1992), por acción de inteligencia del Grupo Especial de Inteligencia (GEIN) comandado por el Crnl. Benedicto Jiménez y por el Gral. Antonio Ketín Vidal de la Policía Nacional. Paradójicamente, por entonces el grupo GEIN era acosado por VMT y los servicios de inteligencia del gobierno.

Los detractores del movimiento de los derechos humanos señalan que el respeto a los DD. HH. es el obstáculo insalvable para la lucha antiterrorista. Acusan de cómplices del terrorismo a los luchadores pro-derechos humanos, porque según aquellos los organismos de DD. HH. no se pronuncian ni condenan los atentados.

\section{Estigma caviar}

"Caviar" es una palabra que proviene del francés y que inicialmente fue utilizada para designar a izquierdistas de la clase media o alta, con hábitos sociales contrarios a su ideología.

En la actualidad, el término caviar es usado para descalificar a los sectores comprometidos con temas sociales, civiles y éticos. Así, para los fujimoristas los defensores de los derechos humanos son terroristas, brazo legal del terrorismo, tontos útiles u oportunistas que viven de los pingues sueldos que les asignan las ONGs progre-“caviares” (supuestos izquierdistas filoterroristas). También, los jueces que dictaron la sentencia contra AFF y sus más inmediatos colaboradores, los medios de comunicación que esperaban una condena, los grupos defensores de la democracia y hasta la Defensoría del Pueblo estarían copadas por "huevos de esturión". Igualmente, para ellos los ecologistas, las feministas, los luchadores sociales son comunistas reciclados. El día que se dictó la sentencia contra Fujimori, en los exteriores del local de la DIROES (Ate), las portátiles de caras pintadas de color naranja gritaban desaforadamente: !Abajo los caviares! 


\section{Angustia y pérdida del decoro}

Desorientados por la angustia que les causó la condena judicial, los voceros fujimoristas amenazaron también con acudir a instancias internacionales como la Corte Internacional de la Haya o el Tribunal Penal Internacional para demandar la anulación de la sentencia, aún conociendo plenamente que esos fueros respetan escrupulosamente la autonomía judicial de los países. De igual modo, la esposa de AFF, Satomi Kataoka, hizo conocer que gestionará ante el gobierno japonés para que este interponga una demanda contra el Estado peruano ante la Corte Internacional de la Haya, porque el Poder Judicial peruano ha condenado a un súbdito japonés.

\section{Recurso de Nulidad y Búsqueda de Impunidad}

El 23 de abril, la defensa de AFF presentó el recurso de nulidad de la sentencia de 25 años ante la Sala Penal Transitoria de la Corte Suprema. Con ello el ex dictador busca el sueño de la impunidad, a la cual nunca accederá porque los tiempos han cambiado a favor de la consolidación de la democracia en el Perú y en el mundo. Dada su impecable consistencia jurídica, la sentencia deberá ser ratificada, lo cual genera pánico en el entorno fujimorista. En el lapso de 6 meses la Primera Sala Penal Transitoria resolverá el pedido de nulidad de AFF. Su abogado César Nakasaki insistió en la inocencia de su defendido.

\section{Indulto}

La emboscada narcosenderista de Sanabamba (9-04-2009) en el VRAE (Valle de los ríos Apurímac y Ene), en la cual fueron asesinados 15 efectivos del ejército, fue utilizada por la cúpula fujimorista y su resonancia mediática para demandar el indulto presidencial a favor del condenado AFF, afín de que conduzca la lucha exitosa contra el narcoterrorismo asentado en el VRAE, puesto que supuestamente fue él quien derrotó al terrorismo y pacificó el país. Utilizar la tragedia del VRAE con este abyecto propósito constituye una inmoralidad tanática.

De otro lado, el abogado y congresista Rolando Souza, miembro de la cúpula de AFF afirmó: "Solamente el fujimorismo va a indultar a Fujimori" (La Primera, 18-05-2009).

\section{Keiko salvadora}

Los fujimoristas presentan a la hija primogénita de AFF, Keiko, como la salvadora del Perú de los remanentes terroristas en el VRAE, la única capaz de indultar a su padre y de "continuar con las obras" del mismo; sea mediante su acceso a la presidencia de la República en el 2011 o con la obtención de una representación congresal importante que le dé capacidad negociadora y poder para imponer sus propósitos, direccionados a lograr la soñada excarcelación de su progenitor. Importantes bolsones de ciudadanos pertenecientes a los segmentos sociales D y E, constituidos por fanáticos seguidores de su padre, así como por prosélitos eventuales captados por la publicidad durante el megajuicio, y también, por la condición de rostro nuevo de ella en el escenario electoral, conforman principalmente su potencial caudal electoral registrado en las encuestas de intención de voto. Además, ella cuenta con un pequeño y eficaz equipo político con creciente posicionamiento mediático 
e ingentes recursos económicos para financiar sus objetivos inmediatos, mediatos y a largo plazo. Ahora, el autoritarismo se cierne sobre el Perú como una peste hereditaria. Ella encarna el fujimorismo recargado: autoritarismo más liberalismo empresarial, para preservar el modelo económico neoliberal. Su mensaje subliminal en la campaña electoral bien podría ser: "Quieres liberar a papi? !Vota por la hija!". Su estrategia sería ingresar a la segunda vuelta electoral y en adelante disfrazarse de "mal menor" para ganar la elección, luego indultar a su progenitor. Una jugada aparentemente genial de esta candidata "antisistema".

En el ansiado sueño de recuperar el poder para usufructo de la camarilla fujimorista, el actual vicepresidente de la República, vicealmirante AP (r) Luis Giampietri, expresó su apoyo a Keiko Fujimori "porque garantizaría que el país continúe en la senda del progreso en la que estamos" y porque "Keiko es una mujer que está formada a los criterios que su padre utilizó en la primera parte de su gobierno". Según él, en la década del 90 se "sentó las bases para esta bonanza que tenemos ahora" (Augusto Álvarez Rodrich, "Giampietri el keikista soy yo". La República, 20 de mayo de 2009")

Sin embargo, la sra. Keiko hasta la actualidad no ha logrado aclarar ante la opinión pública por qué asumió el cargo de Primera Dama de la Nación durante la dictadura, sustituyendo a su madre, la sra. Susana Higuchi, esposa de AFF, quien la estafó, la habría hecho someter a humillantes maltratos y enclaustramiento, cuando ella siendo Primera Dama de la Nación denunció (marzo de 1992) el tráfico de ropa usada donada por ciudadanos japoneses para ayudar a las familias pobres del Perú. Higuchi acusó a la familia de su esposo de haber montado esa corruptela en el APENKAI (ONG de la familia Fujimori, que administraba los fondos donados por ciudadanos japoneses), y que dirigían los hermanos Santiago y Rosa Fujimori y el esposo de ésta, Víctor Aritomi Shinto. En su perfil público, pareciera que la Sra, Keiko sólo tuviera padre y no madre. ¿Esto es ético?

Tampoco, la candidata presidencial fujimorista ha explicado al país con qué dinero se financiaron los costosos estudios escolares y superiores (de ella y los de sus tres hermanos), estos últimos en universidades de Estados Unidos, por un monto total 1'225,000 dólares, que incluye pago de pensiones, viajes, alquiler de departamentos y manutención. Mientras que AFF informó al Poder judicial que la remuneración total que percibió como presidente de la República durante los 10 años de gobierno fue de 148, 000 soles (La República, 1805-2009). Su sueldo como presidente era dos mil soles mensuales. Sus testimonios y los de VMT muestran una flagrante contradicción. Por su parte, ella, el 19 de mayo de 2009 declaró que "es absolutamente falso que haya recibido un solo dólar de Montesinos para costear el pago de mis estudios y los de mis hermanos"; mientras el ex asesor presidencial, el 25 de abril de 2002, declaró ante la comisión investigadora del Congreso que "el pago de los (estudios de los) hijos se hizo con dinero en efectivo que yo le entregaba a él (AFF)". (El Comercio, 24 de mayo de 2009). En aquella oportunidad, VMT también reveló que dicho dinero procedía de los fondos de los ministerios de Defensa y del Interior, desviados del Sistema de Inteligencia Nacional. Por su lado, la ex congresista Anel Townsend declaró que Keiko Fujimori, luego de caer en contradicciones, se negó a seguir declarando como testigo ante la comisión del Congreso que investigó el origen, movimiento y destino de los recursos financieros de VMT y su relación con AFF. En dicha oportunidad ella manifestó: 
"Me acojo al derecho de guardar silencio". Townsewnd, afirmó que entonces, sobre las cuentas de Keiko Fujimori no hubo ninguna investigación. (La Primera, 23 de mayo de 2009). Son silencios que hablan a gritos.

\section{Doble juego político}

La cúpula fujimorista se mueve activamente en dos frentes paralelos. Por un lado, tiene protagonismo en el juego democrático en el Congreso, en el ejercicio del poder compartido con el partido de gobierno y en el escenario pre-electoral; y por otro lado, petardea la democracia al subvertir la institucionalidad, descalifica al tribunal San Martín que emitió la sentencia y altera el orden público mediante la movilización de sus bien remuneradas portátiles.

\section{Inicio de la campaña electoral}

Durante su alegato final, en el megajuicio, AFF lanzó un discurso puramente electoral a favor de sus hijos Keiko y de Kenyi, designándolos antes los jueces como los continuadores de su estela política. Él, no se dirigió a sus juzgadores, habló para los electores del 2011. Seguidamente, dirigentes del movimiento que impulsa la campaña electoral de la sra. Keiko realizaron magras manifestaciones en el Anfiteatro del Parque de la Exposición, luego pretendieron efectuar un mitin de "desagravio" a Fujimori en el limeño distrito de San Juan de Lurigancho, el cual debido a la pobre concurrencia de manifestantes, no se efectuó y la candidata presidencial, "heredera de la dinastía", tampoco estuvo presente en el escenario. En una analogía sarcástica con la presunta presencia del primer caso de influenza $\mathrm{AH} 1 \mathrm{~N} 1$ o gripe norteamericana en Lima, la revista Caretas denominó este fiasco como la versión política de la "gripe porcina", "gripe fujimorista", "fiebre naranja" o "virus fujimorista".

Keiko Fujimori, en mitin del 8 de abril de 2009, alentando a sus acólitos manifestó: "el fujimorismo seguirá avanzando. Hoy estamos primeros en las encuestas y seguiremos así". En efecto, un $25 \%$ de intención de voto a su favor la ubica en el primer lugar en los sondeos de opinión.

Respecto a este evidente hecho de identificación de la víctima con el agresor, el escritor Mario Vargas Llosa, ante la pregunta periodística, ¿Cómo explica que a propósito de elecciones democráticas surgen dictaduras?, él respondió: "En algunos casos por la ignorancia y en otros casos por la inmadurez política de los países. ¿A ti no te parece absolutamente extraordinario que la hija de un dictador, que acaba de ser condenado a 25 años de cárcel por crímenes contra los derechos humanos, que ha saqueado al país en actos flagrantes de inmoralidad pública, sea la candidata que tiene más chance según las encuestas de opinión? Eso revela unos niveles de inmadurez política terribles. Por eso creo que las personas, digamos, más lúcidas tendrían la obligación en debate cívicos, para impedir que la pasión, la frustración, el resentimiento lleven al Perú una vez más a los desastres que han sido todas las dictaduras en nuestra historia, sin una sola excepción" (La República, 19-05-2009) 


\section{Cobertura mediática}

No pocos medios de comunicación nacional, cotidianamente, se coluden con la estrategia fujimorista para la ansiada recuperación del poder del Estado. Así, de manera creciente se observa que medios de comunicación escritos, radiales y televisivos se esmeran en hacer comedidas, complacientes o aduladoras entrevistas a la heredera de la dinastía Fujimori y a "grabar en el disco duro" de la frágil memoria de los peruanos que gracias a su padre se acabó con el terrorismo y la crisis financiera de la década del noventa.

Paralelamente, dichos medios orquestan toda suerte de malas artes contra los líderes que les son adversos, y desarrollan viles campañas de agravios y de demolición de sus opositores hasta hacerlos capitular. Entre los medios que abrazan la causa fujimorista están La Razón, El Expreso, El Correo, La Hora N, El Francotirador y Punto Final, entre otros.

\section{Nunca más}

Nunca más debe darse en el Perú un gobierno autoritario y amoral. La peruanidad profunda e íntegra debe comprometerse para que este reto histórico no quede en una mera ilusión. En este sentido, hay que desengañar a quienes presumen que pueden "fujimorizar" el proceso electoral del 2011. Para ellos, la sentencia de la memoria, el museo de la memoria y la comisión de la verdad destinados por la conciencia nacional para que no se repita nunca más esta catástrofe en el Perú, carecen de valor alguno. En este sentido, en opinión de Vargas Llosa, la condena contra AFF debe servir como "escarmiento preventivo" para los potenciales autócratas.

\section{Soborno a Montesinos}

El 11 de mayo de 2009, debió iniciarse el nuevo proceso judicial contra AFF, acusado por el delito de peculado y falsedad ideológica. Al respecto, en diciembre de 2005 cuando defendía al ex ministro de Economía, Carlos Boloña Behr, César Nakasaki responsabilizó a AFF por el pago irregular de 15 millones de dólares (52' 500, 000 soles) por concepto de Compensación por Tiempo Servicio (CTS) a Montesinos, provenientes del Tesoro Público a razón de 1.5 millones por cada año de servicio. VMT había manifestado que sólo ganaba 1400 soles mensuales como asesor presidencial. Según la confesión sincera de Boloña, AFF lo obligó personalmente a firmar el Decreto de Urgencia $N^{\circ}$ 081-2000 (19-09-2000), que transfirió los 15 millones de dólares al Ministerio de Defensa, supuestamente para financiar un imaginario Plan Soberanía, para repotenciar a las tropas acantonadas en la frontera con Colombia e impedir la incursión de las Fuerzas Armadas Revolucionarias de Colombia (FARC) en esa zona. En realidad esta coartada fue una "indemnización" para comprar el silencio de Montesinos y que aceptara dejar el cargo de asesor. De esta manera intentó solucionar el problema de gobernabilidad que se generó en el país a raíz de la difusión del video Kuori-Montesinos. Aquel Decreto de Urgencia fue redactado en el despacho del entonces ministro de Economía, Carlos Boloña.

Así mismo el 23 de setiembre de 2000, VMT fugó a Panamá y dos días después Fujimori emitió la Resolución Suprema $N^{\circ}$ 424-2000, donde aceptaba su renuncia y le agradecía por "los importantes servicios prestados a la Nación" (Caretas, 14 de mayo de 2009). 
Entre ambos siempre existió una mutualidad siniestra.

De otro lado, la opinión pública se muestra mucho más sensible ante los actos de corrupción que ante los crímenes de lesa humanidad. Así, días antes de iniciarse el juicio por esta causa, una encuesta del Instituto de Opinión de la Universidad Católica reveló que el 70\% de los entrevistados consideraba culpable a AFF.

\section{Opinión de Vargas Llosa}

Según el escritor Mario Vargas Llosa, la sentencia “trasciende largamente la demarcación geográfica peruana y gravita a partir de ahora sobre toda América Latina como una advertencia a quienes, de un confín a otro del continente, aspiren a tomar por asalto el poder y gobernar amparados por la fuerza". "Se trata de un precedente histórico señero para quienes soñamos con una América Latina emancipada para siempre de la peste autoritaria". "Qué extraño y qué hermoso lo que nos ha ocurrido en estos últimos días, advertir que el Perú del que habla la prensa y las personas en la calle, con respeto y admiración, es una civilizada nación que enfrenta su pasado con dignidad y coraje, y donde un tribunal civil, juzga y sanciona los crímenes de un dictador. Un ejemplo para América Latina, sí. Y para el mundo entero" (El Comercio, 19 de abril de 2009).

\section{CONCLUSIONES}

El fenómeno Fujimori es el espejo de la situación tragicómica de la salud mental en el Perú, reflejada patéticamente en el ethos político nacional, en el cual se revela la inveterada disposición al masoquismo, el bajo nivel cultural, la baja autoestima, carencia de identidad, sumisión, dependencia, desconfianza colectiva, anomia social y abierta tolerancia de la corrupción, entre otras taras de grandes sectores de la población pobre y en pobreza extrema. Ante ello, urge:

1. Exorcizar a la sociedad peruana de la seducción mórbida por la autocracia.

2. Recusar como amoral la existencia de la pobreza, pobreza extrema y la riqueza extrema.

3. Erradicar los patrones psicosociales disfuncionales, tales como: miedo, rencor, maltrato, anomia, envidia, mediocridad y conformismo, entre otros lastres.

4. Forjar una nueva clase dirigente, dispuesta a servir a los intereses nacionales y a las mayorías pauperizadas.

5. Aprender a elegir a los políticos mejor preparados y descartar a los outsider, improvisados, oportunistas, manipuladores, incompetentes, tránsfugas y a los politiqueros de oficio.

6. Cesar el entornillamiento en el poder de las cúpulas políticas al servicio de intereses particulares o de grupo, excluyentes.

7. Erradicar el ejercicio de la patología del poder, mediante procedimientos democráticos. 
8. Combatir frontalmente la corrupción en cualquiera de sus manifestaciones y donde se le detecte.

9. Deslindar claramente entre la democracia auténtica y la pseudodemocracia autoritaria.

10. Erradicar el enquistamiento de los grupos de poder en la gestión del Estado.

11. Desenmascarar y vacar a los políticos corruptos, mendaces y demagogos.

12. Sanear los poderes del Estado: Ejecutivo, Legislativo y Judicial.

13. Priorizar la educación como política sostenible de Estado.

14. Educar a los niños desde el hogar y la escuela, forjándoles sentimientos superiores, principios y valores ético morales.

15. Incorporar la salud mental como política de Estado a favor de las mayorías olvidadas.

16. Aprender a ejercer ciudadanía y la defensa de los derechos humanos.

17. Vigilar la transparencia en el ejercicio del poder del Estado mediante el control institucional, mediático y ciudadano.

18. Desarrollar una institucionalidad fuerte al servicio de la sociedad y del país.

19. Fortalecer el Estado de derecho, el contrapeso de poderes, la libertad de expresión y el empoderamiento ciudadano en el ejercicio de la democracia.

20. Desarrollar el proyecto de desarrollo nacional a largo plazo, con participación de la sociedad civil organizada.

Con educación, salud mental y espiritual, el Perú será una nación gobernable, rumbo a convertirse en un país desarrollado. Que así sea.

\section{REFERENCIAS BIBLIOGRÁFICAS}

1. Jara Umberto (2007). Ojo por ojo la verdadera historia del grupo Colina. Lima: Página editores.

2. Hirigoyen M.F. (1999). El Acoso moral. El maltrato psicológico en la vida cotidiana. Barcelona: Ediciones Paidós Ibérica S.A.

3. Nizama, Martín (2001). "La década dantesca de Fujimori y Montesinos". Revista del Foro. Edición especial. Lima: Colegio de Abogados de Lima, 2001;1(1);67-124

4. Nizama, Martín (2008). "Psicopatía política: caso Fujimori". Revista de Investigación en Psicología 11(1); 11-36. Lima: Instituto de Investigaciones Psicológicas, Universidad Nacional Mayor de San Marcos.

5. Burt Jo-Marie (2009). Violencia y autoritarismo en el Perú: bajo la sombra de Sendero y la dictadura de Fujimori. Lima: IEP Instituto de Estudios Peruanos, Asociación SER. 